\title{
Hiperreal Dimension of Dying: Reception of the Phenomenon by Jean Baudrillard, Zuzanna Janin, and Bogna Burska
}

\author{
Michalina Guła \\ University of Opole
}

\begin{abstract}
The first part of the paper presents the philosophical concept of Jean Baudrillard in which the issues of death and dying constitute an essential theme. Contemporary times in which the human condition seems to be extremely difficult are presented in a somber way. Isolation from nature results in the existence filled with fear of death. Natural death is a mentally inconceivable occurrence, an embarrassing phenomenon, and therefore unworthy of being remembered. Only sudden, spectacular death creating media hype seems to be meaningful and worth paying attention to. Instant death is set in opposition to slow death which is also called postponed death. Death in the heat of work, duties, obligations, and prohibitions is the death inflicted at the request of both an employee and an employer. Work rewarded with payment is an act of temporary suspension of death. Burdened with work, people forget about the debt they have incurred from nature. A contemporary employee does not deserve death and instant death is only act of salvation, the act of free will. The second part of the paper focuses on artistic activity of Zuzanna Janin and Bogna Burska. Both artists deal with an issue of media death using different means of expression. Spinning their narratives of intimate decaying and media rage in a public space, they correspond with the Baudrillard's philosophical thought.
\end{abstract}

Keywords: Jean Baudrillard, Zuzanna Janin, Bogna Burska, violent death, intimate death, corps, media hype, art of work

Despite of its universality, death becomes more and more socially unaccepted phenomenon in contemporary times, erased from the social consciousness. Death arouses ambivalent emotions, brings forth fascination and revolt, enslaves and frustrates more than ever before now.

How do we define death today?

Definition of death must explicitly define/catch what we usually understand by the word death in colloquial use even before doctors decide how to ascertain, based on medical knowledge, that a patient has died... one needs much more than only a definition. Definition as such does not decide on the status of a patient of a completely and permanently defunct brain, hooked up to a respirator. This type of conclusion depends solely on the death criterion we apply in a given case. The definition of death is first of all the task of philosophy. But determination of a death criterion belongs primarily to medicine. $^{1}$ (Bernard Gert et al. 2009, 392)

As medical technology develops, we are able to determine death criteria in an unfailing and unambiguous manner. Modern technocracy transforms the natural environment of death into a strange and abstracted phenomenon. Baudrillard states:

Michalina Guła, Master of Philosophy, Ph.D. student, Department of Social Science, Institute of Philosophy, University of Opole, Polnad; main research fields: Philosophy of Art, Contemporary Aesthetics, and Contemporary Art. Email: leks@op.pl. 
Evolution leading from primitive societies to modern ones is of irreversible nature: alongside, the dead gradually cease to exist. They are thrown out of the area of symbolic exchane taking place within the group. They are not rightful beings any more, good partners of exchange, which they are painfully made aware of, excluding them increasingly from the group of the living, rejecting them, throwing out from their homesteads where they were living in intimate closeness with the living to a desolated cemetry located inside a village or within the town walls, then assuming the shape of the first getto being the archetype of the succeeding ones, moving them away farther and farther from the centre to the outskirts to place them eventually — as it happens in modern cities and metropolies — to nowwhere, that is, where nothing is to be expected, neither in physical nor mental space. ${ }^{2}$ (Jean Baudrillard 2007, 158)

Madness of modernity manifests itself in obsessive desire for the control of life and all its symptoms. All social units act, at least formally, to improve the quality of life and to extend it. Death stands in the way of execution of the foregoing primary objectives; it is acceptable only in categories of medical accurateness of statistical analyses, death expressed in numbers does not evoke just objection, yet. It is abstracted, logically conditioned, and scientifically useful. As an intimate process, death becomes a taboo subject, the problem we would like to forget quickly. Natural death is perceived in terms of anomaly, a completely inhuman phenomenon. A corpse - tense, passive, devoid of life — is disgusted though at the same time hypnotised, along with death; the corpse loses personality, and along with this loss, it becomes nobody's matter, artifact, unwanted, deprived of its selfhood. A dead body, as biologically inactive phenomenon, is a mentally incomprehensible and inexplicable act of disagreement to the idea of life. A corpse, full of impudence and nonchalance, manifests something totally irrational, through its presence; it expresses fragility of human existence, broken dreams, takes a negative attitude towards rationalisation and announces far-reaching inefficiency of the system.

Death manifests its victory directly through the matter's slow chemical and biological decaying. This scenery makes one sick; tardiness in disposing the bodies of the deceased poses an epidemiological threat and, what is more, breaks actions of the living calculated for success. In the system of cooperation work, an instant death of an employee undercuts work efficiency. Banishment of the dead results from their non-compliance with formal and social requirements imposed on each citizen by law and by the obligation to work. Therefore, the corpse acquires the status of an outcast, deprived of social affiliation and the right to come back from where it exists in vacuum, beyond the pale. Loneliness of the decedent is expressed in the total lack of community with the living as well as with other dead exiles. The necropolis, constituting deposits of artifacts of death, is a chute of rejected truths and civilisation fears. "The dead are placed in a zone of radical utopia $—$ not even just grouped, arranged, and alloted, but annihilated. They just evaporate" (Jean Baudrillard 2007, 158). ${ }^{3}$ The social denial of death from the consciousness of the living does not solve anything. The isolated, condemned, and lone dead revives, immortal forever. The living, scared stiff by the unknown, with a delayed death warrant, remains mortal. Only death brings consolation and gives relief.

Nowadays, immortality has become a privilege of the masses. In the old days, immortality was the sign of greatness, authority, recognition, today it is democratised and becomes the right of all. The immotral have lost the status of the exalted; they do not coexist with the living; and they function in the zero zone. Threat of the living against exclusion is a perfect tool of terror, which effectively affects the operation of the control system. The social rejection of death makes it possible to exercise powers over an individual more radically and successfully. Terror of death deprives the living of spontaneous and conscious functioning in the world, the authority having custody of fear effectively cared for divests the individual of the right to death. Death is not just the act of surrender but the act of freedom. Everything else can be rationally arranged, controlled, 
transformed, and estimated. Life and death have become two alienated worlds against each other; death estimated by a scientific paradigm has lost its former spiritual nature. Old cultures hosted the dead in their homesteads, and the world's spiritual nature has been transformed over times into the sterilized world of techne. The spirits of old ancestors have been isolated; death has obtained carnal dimension; bodies of the dead rest on sterilized catafalques raising walls of indifference against what is unknown and unquantifiable. The silent cemeteries and ruins of old worlds evidence the erstwhile passionate bonds of death and life.

We still continue to exchange with the dead even if we deny their existence and refuse them the right of stay in our world — break of exchange with the deceased is just redeemed by our own constant dying and fear against it... Only the preposterous theory of freedom can claim that we have got rid of the dead, that the incurred debt is of universal nature and cannot be repaid, and we will never succeed to repay this freedom we have pocketed. ${ }^{4}$ (Jean Baudrillard 2007, 169)

Death in primitive cultures was undergoing a symbolic exchange, rituals of calling spirits, initiation, ensured a vital connection between the dead ancestors and the living. Nowadays, this process is replaced by economic exchange/trade. In contemporary times, we are subject to death in our lifetime. A contemporary man is subject to symbolic violence; he undergoes a slow death harnessed into fetters of work. The toil is balanced with a salary. The antithesis of work constitutes an instant death which seems to be the most original, natural death. Each sign of life is a postponed death sentence. By a temporary act of grace, the employee is deprived of the right of choice and life is flamboyantly imposed on him. The employer is obliged to grant a holiday leave to the employee and his work is rewarded with a salary. Therefore, the employee actually works for his own slow dying when he does not work but rests. Death is the domain of free men; the employee does not deserve the honour of death. The employee has been divested of his authenticity, humiliated, left with painful and deadly fear against the inevitable. The real act of freedom, the act of actual redemption, remains death par excellance, an ultimate instant death, biologically unambiguous. A contemporary employee is ashamed of keeping pace with death; he is afraid of being ridiculous, intoxicated with fear, so he accepts modern slavery. A modern master does not take the employee's life but commands to live, "paradoxically, the worst wrongs they are inflicted on, is just they are denied to die. Such postponement of death makes them slaves, sentencing them definitely to the life of misery they owe to labour" (Jean Baudrillard 2007, 57). ${ }^{5}$ Primitive measures of violence administered by the old rulers came down to the acts of physical violence and death penalty, not very effective in our times. Today, the most dangerous sentence for the accused is the life under constant control and rationalisation. The act of clemency which may be performed only by the accused himself is to restore the individual's right to die. Then, the right to posponed death shall be returned to the employer and the instant death should be executed. Since, only such death gives respect for human esteem, returns his dignity, and gives the status of authenticity.

Intimate and lonely death in the quietness of the house outside the walls of a medical conglomerate is a more and more rare phenomenon. The tasks of physicians come down then to setting down the causes and specifying the date of death. When death turns out to have been caused by the natural order of things - the resultant of old age, it ceases to be a particularly interesting event. Spectacular death, full of unknown circumstances, criminal, and multi-threaded, erouses the greatest emotions. It becomes media-essential, meaningful, and significant to the compassionate receipients of the hypereality. Death in the telephoto lenses is an honour, which arouses unrestrained curiosity of kinsmen and hidden jealousy of the television viewers. Death understood as such, in the media limelight, moves our imagination and that is why media deliberately 
abound so much in violance. Drastic scenes full of bloody pictures contrast with the picture of a common, silent, and bashful death. Contemporary culture is culture of accidents, as Baudrillard predicates quoting the words of Octavio Paz. An accident is an unpredictable, sudden, and unexpected process where the invisible everyday heroes become mythical heroes. Through their sudden, not directed, unforseeable act of death, they destabilize the existing social order for a while; everyday monotony is replaced with an eventful spectacle. Post-mortem heroes pacify social tension with their feat. Hysteria of collective despair has therapeutic effects on the society. Faced with media death, all come close to one another, and a sense of community encourages the induvidual to dialogue with the other. Social instinct has been fulfilled.

We are facing here a collective passion. Violent death or death resulting from a disaster does not satisfy individual consciousness manipulated by obscenic mass media (such perspective is referential one and morally distorted); we are deeply moved rather because they affect the entire group and refer to the passion of the group with regard to itself, transforming its shape somehow or other and allowing it redeem itself on its own eyes. ${ }^{6}$ (Jean Baudrillard 2007, 209)

Violent death is a clear message, not non-veiled, its meaning is directly perceptible, and mass media remain totally impartial while portraying death by accident. Mortality of the heroes in a violent act of death is the contradiction of the idea of postponed death, a negation of the obligation to work. The corpse which decays and does not work, is a rebel, revolutionist, which stirs up and frightens the viewers with its authenticity. Intimate/natural death which does not arouse a collective hysteria, is not connected with a social agitation which does not result in the community's collective mourning. Thus, it is socially useless.

The motif of death and dying constitutes a key issue of the works of Zuzanna Janin. The artist creates covers: A human body is such tangible biological cover. This cover - human body, is being transformed, and is ageing in the process of life; its existence is persistently moving towards death. The artist determines the limits of carnality; she plots stories about human existence and final objective of human life through the lens of what is physical. She asks about the role of the cover in an intimate clash with another man, equally carnal and transient. The physicallity of the body determines the existence of an individual, defines a man, delimits freedom, and allows to feel compassion towards another man in an intimate contact. We inherit physical attributes and character from our ancestors as the result of genetic message, however, how thoroughly original beings, independent and free from biological conditions we would remain. What we are in extremis? Death as the term of physical domestication in the body delimits the end of everything. The artists enquire. Zuzanna Janin expands upon the subject of death, process of dying/decaying, and carnality in the project of 2003 entitled "I have seen my death" which part depicts the artists' fictional funeral. The project comprises many minor artifacts, and among them particularly significant video works "Ceremonies/Games" and "Masonry work." The whole of the project has been suplemented with the record of interviews with critics and artists, newspaper, and the Internet quotes. The project uncovers ambivalent emotions related to the issues of death. Mass media set limits of existence and intensify the sense of mourning; a fictional funeral becomes real and media death allows a fictional corpse to exist in the media spotlight to exist genuinely. Real death, coming in an intimate way without media hype, becomes a dead, pale, and lucid event. Nowadays, we are not able to experience death and accept its harvest in the privacy of our own homes without the obscene media hype. Modern ceremoniality has underwent strong standardization; television mortuary spectacles set out the standards of funeral ceremonies. Media funeral becomes a theatre of political and social debates in which there is no room for intimate reflection. All Saints' Day becomes more and more tawdry and spectacular, and a TV camera brings in disorder, and 
disturbs the silence and intimacy of cemeteries.

The project of 2003 completes another project entitled "Seven Deaths' Executed by the Artist in the Years 2003/2006." Zuzanna Janin presents a "violent death, so media — death, intertwined with a barely visible dance macabre of the naked figure." Zuzanna impersonates herself, creating a game with time which is only possible in art $^{7}$.

The subject of media death is undertaken by another Polish artist, Bogna Burska. In her works, death is not presented directly by the picture of a dead body, but it peers from the visage of fresh blood, splashed around, still beating with life, symbolizing violence and crime. The artist made a symbolic bloody marking in her project called "Stained glass" of 2002; she sloshed a red paint onto the window panes of the desolete ceremonially inoperate Mariavite church in Pogorzel near Warsaw. The soiled, blurred panes with hands reflected herein ominously manifest murderous intentions of the assassins. Constituting bloody artifacts in the place of worship; the artist invokes the Christian tradition of suffering and dedication which are the hallmarks of the attitude of Jesus. The prints of blood seem to be partially wet and partially clotted manifestations of pain, totally human suffering devoid of devine peacefullness and reflection. The slaughter sealed with human attempts to escape from danger flags, a contemporary problem of the death denial. We face our devouring fear of crime instead of sacrifitial death of the Savior, who dies to our salvation and to raise our spirits. The artistic measures used by the artists, expression device of smears of blood, and intensified by the hand prints, emphasize what we are afraid of most: crazy, irrational, illogical, and non-definable acts of madness; we stand fightened and helpless against act of crime. The aesthetics of this project is the aesthetics of horror in style; it sends a strong message and presents tastes of a modern viewer of the hyperreal culture. An intimate drama taking place in a closed church, physical struggles of the victim in order to survive, loneliness, and carnality of death noted with the writing of the clotted blood, is the picture of mentally tame death. The crime lurks and expects its fulfilment. It is also expected by the viewers, fairly hungry for the bloody spectacle they die silently in front of their TV sets in hypnotic impatience.

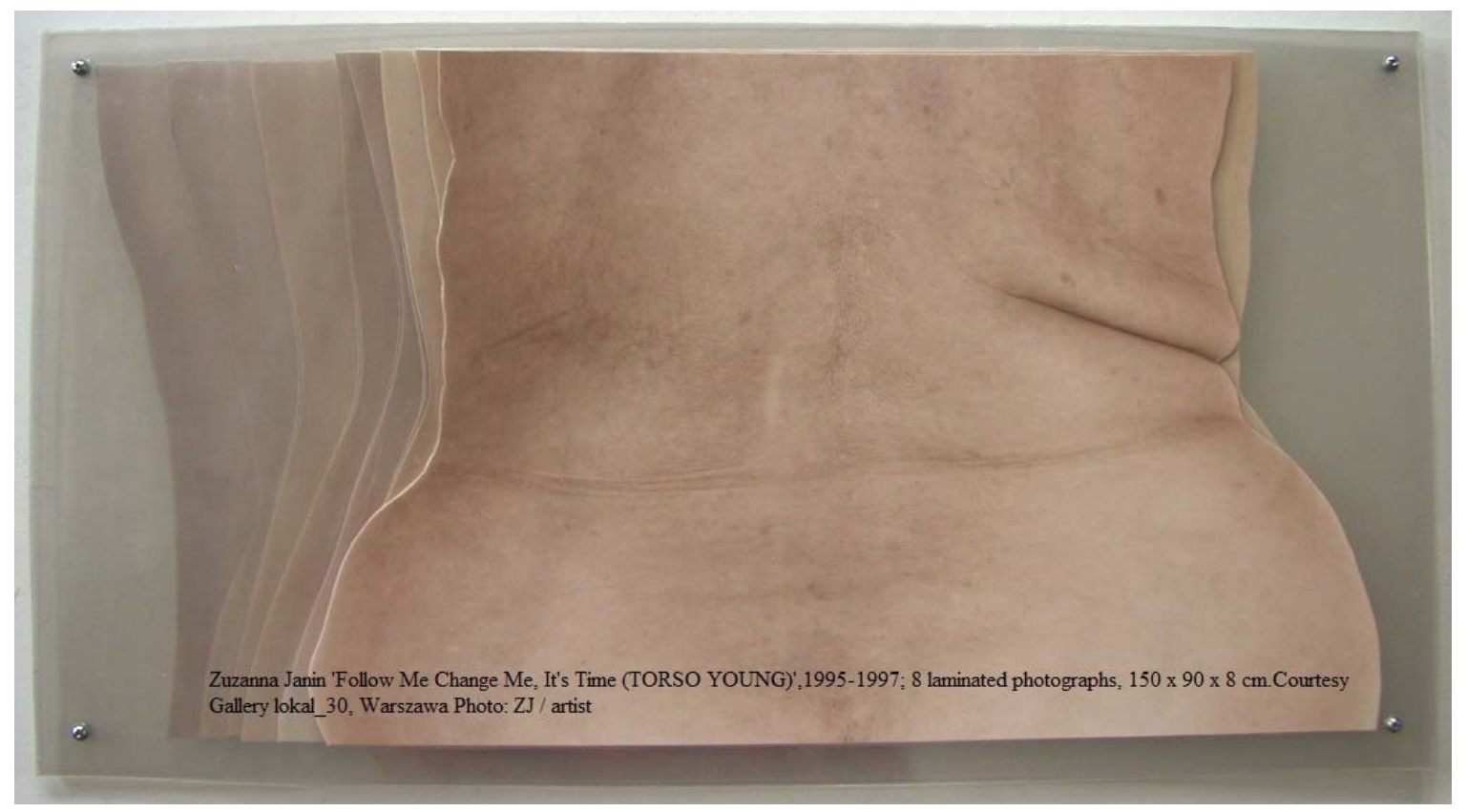



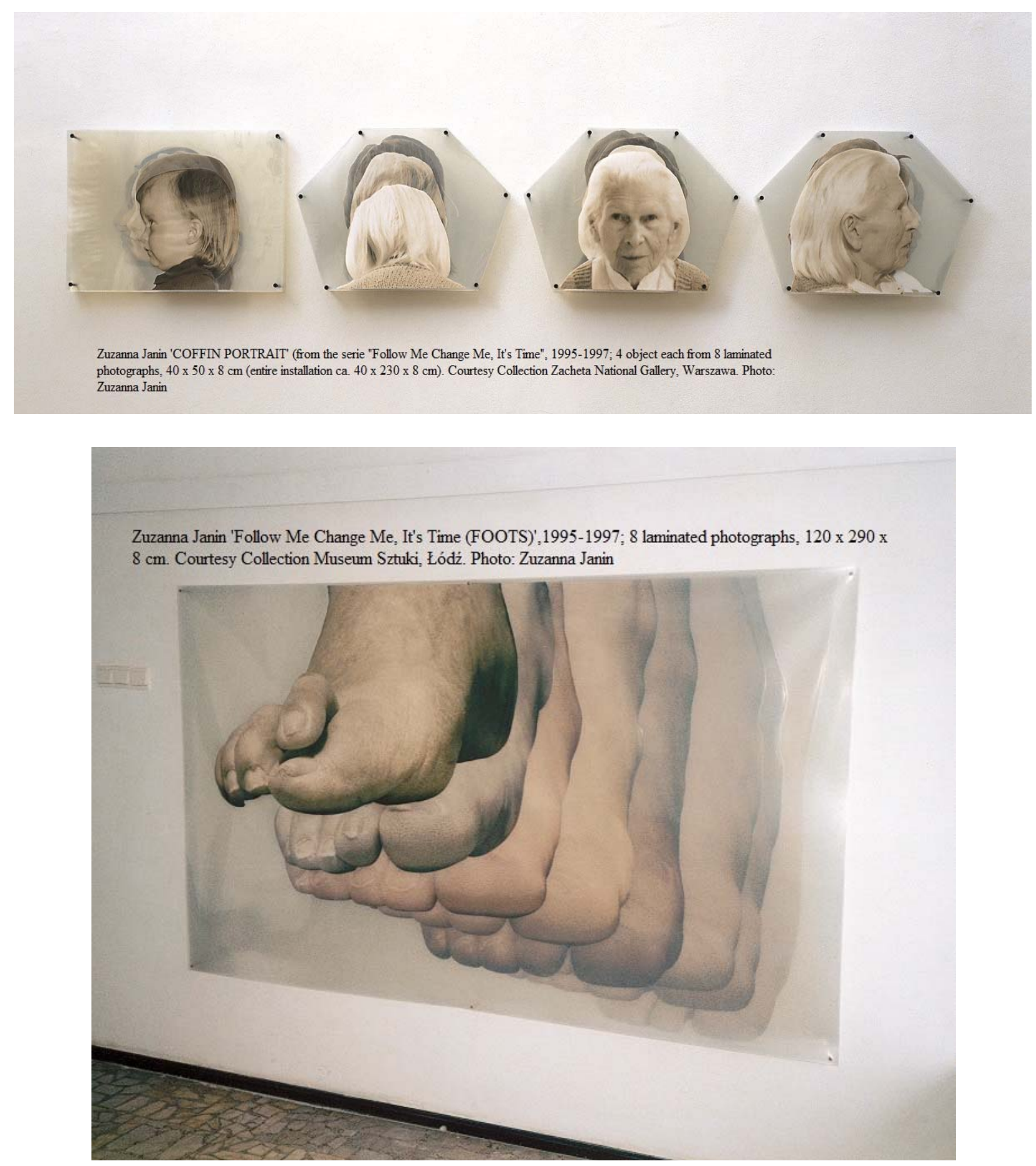

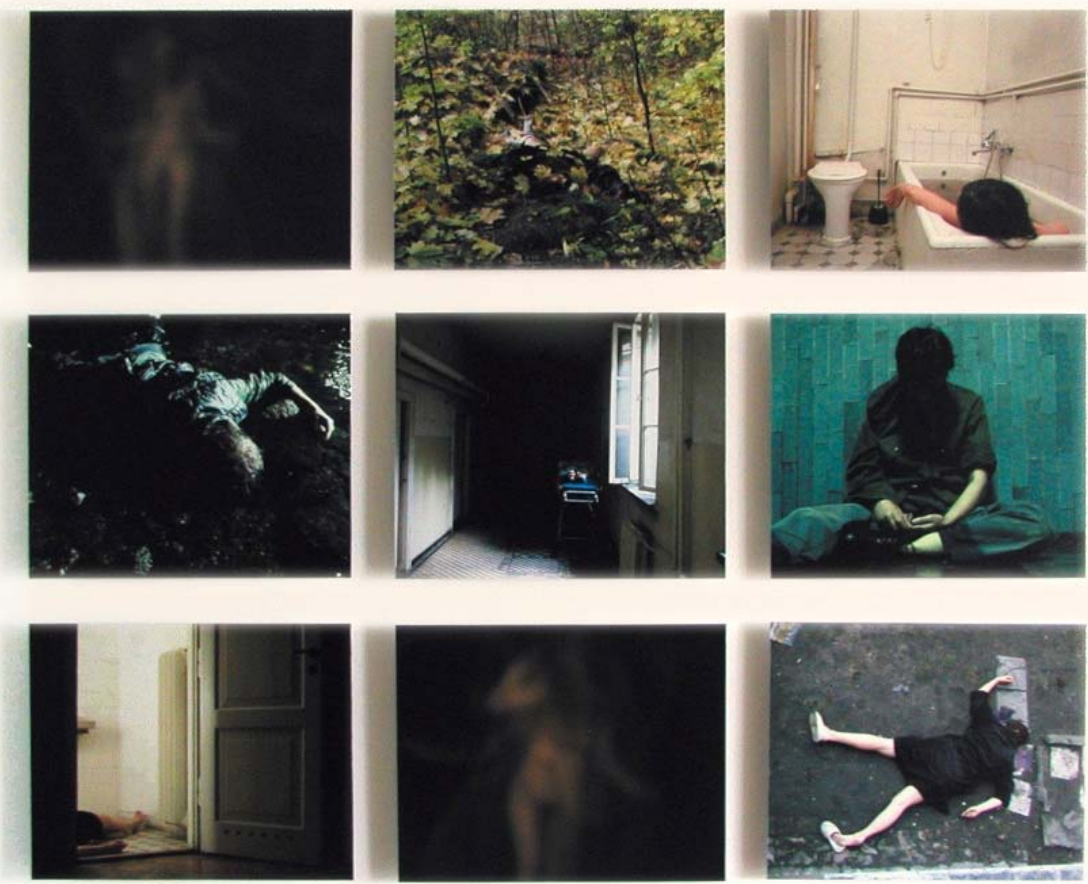

Zuzanna Janin, 'Seven Deaths', installation view, 9 photo on dibond. Courtesy Hoffmann Sammlung Berlin. Photo: ZJ

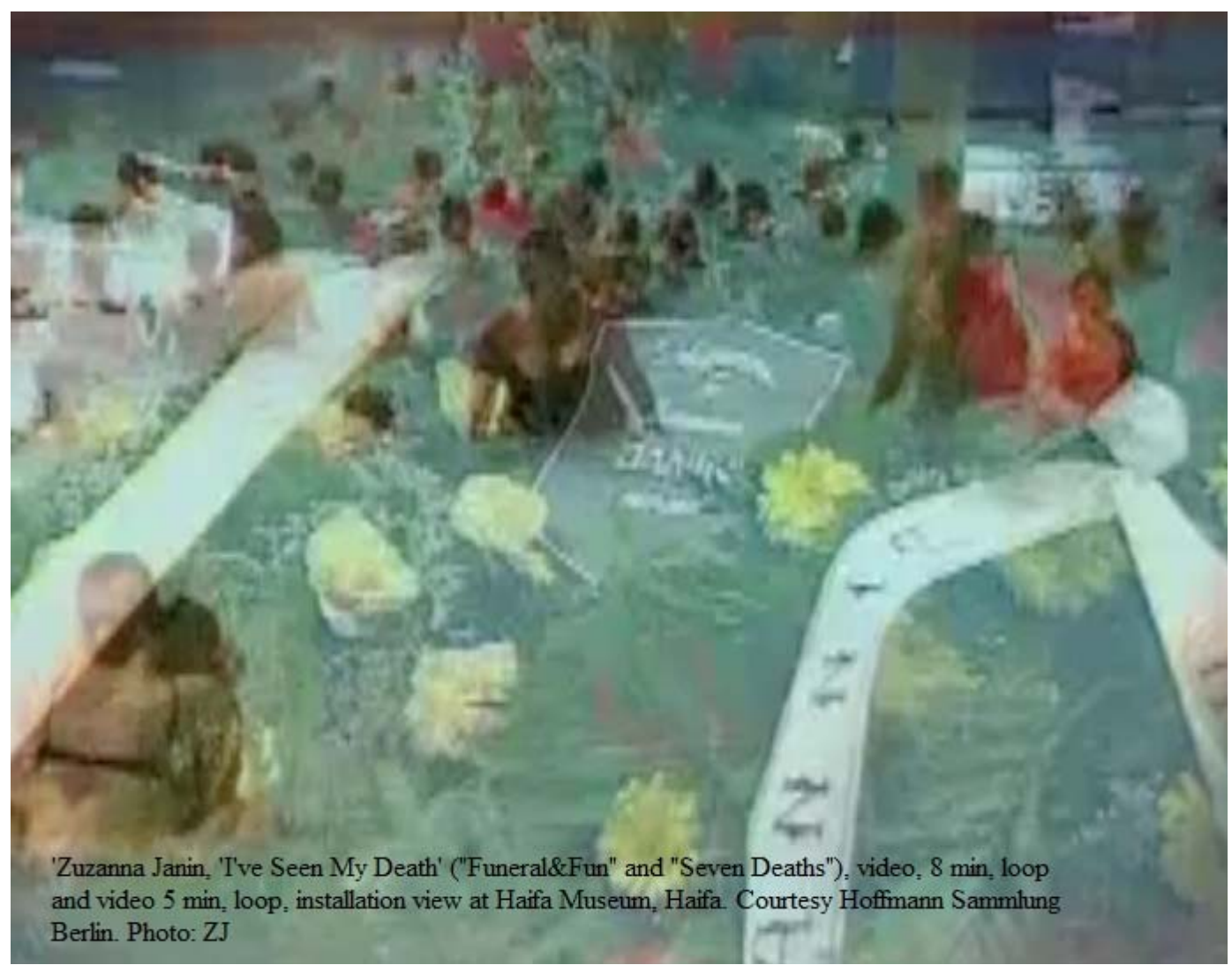




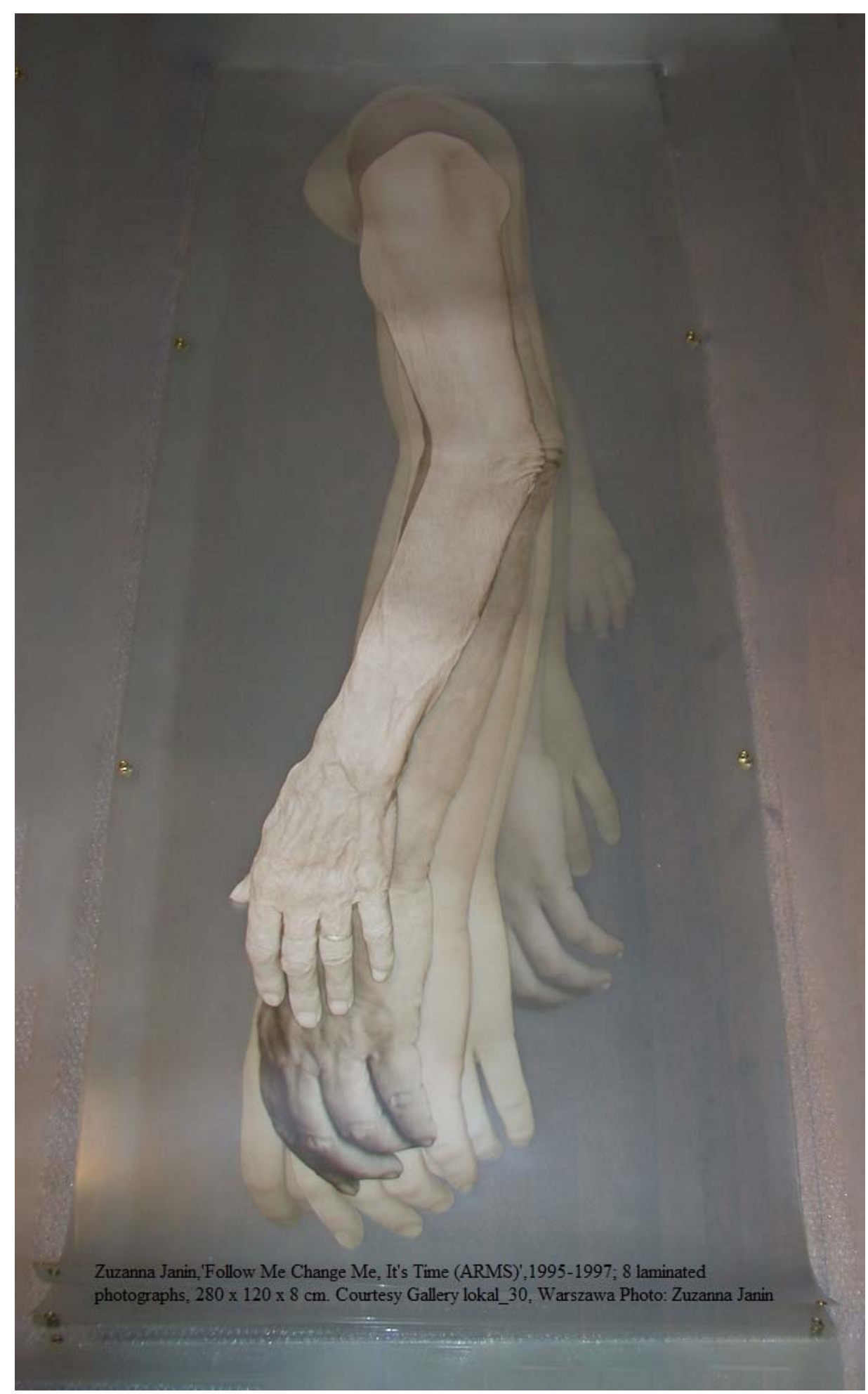




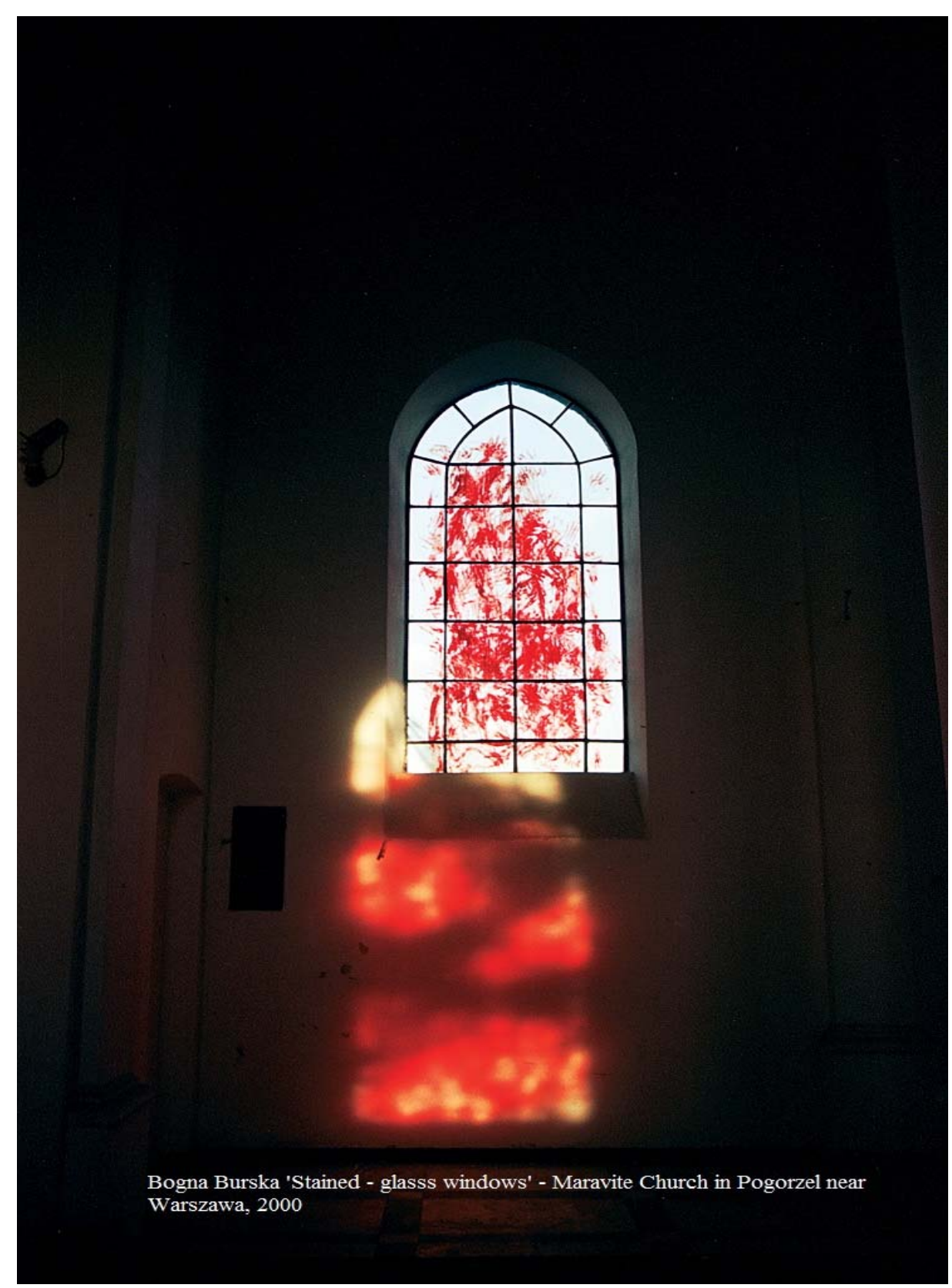

Notes

1. Bernard Gert, Charles Culver, Danner Clouser, Bioetthics. Gdańsk: Słowo/obrazTerytoria, 2009, 392.

2. Jean Baudrillard, Symbolic Exchange and Death. Warszawa: Sic., 2007, 158.

3. Ibid., 158.

4. Ibid., 169

5. Ibid., 57.

6. Ibid., 209.

7. Grzegorz Borkowski, Adam Mazur, Monika Branicka, New Phenomena in Polish Art after 2000, Warszawa: Centrum Sztuki Współczesnej Zamek Ujazdowski, 2007, 186. 


\section{Works Cited}

Bernard, Gert, Charles Culver, and Danner Clouser. Bioetthics. Gdańsk: Słowo/obraz Terytoria, 2009.

Jean, Baudrillard. Symbolic Exchange and Death. Warszawa: Sic., 2007.

Grzegorz, Borkowski, Adam Mazur, and Monika Branicka. New Phenomena in Polish Art after 2000. Warszawa: Centrum Sztuki Współczesnej Zamek Ujazdowski, 2007. 